\title{
An apparatus and procedure for effective instrumental training of neonatal and infant rats
}

\author{
JAMES R. MISANIN, LYLE D. CHUBB, SHARON A. QUINN, and G. EDWARD SCHWEIKERT III \\ Susquehanna University, Selinsgrove, Pennsylvania 17870
}

\begin{abstract}
Following introductory remarks on the necessity of being able to detect learning disabilities and other behavioral impairments in animals at an early age, an apparatus and procedure for the escape training of neonatal rats are described. In this apparatus, both 5- and 7-day-old rats were shown to have improved their performance, in terms of a speed increase, over a 25 -trial training session. A procedure for active avoidance training in the same apparatus is also described and its effectiveness is demonstrated in the behavior of trained 10-day-old rats relative to that of yoked controls. The appropriateness of the described apparatus for the instrumental training of neonatal and infant rats is discussed in relation to that of other apparatuses that have been used for this purpose.
\end{abstract}

Since the early work of Krech and his associates (e.g., Krech, Rosenzweig, \& Bennett, 1962) on the effects of social and sensory stimulation during infancy on behavior later in life, there has been a growing interest in the effects of a variety of prenatal and infantile experiences on the behavior of laboratory animals. In the laboratory, these experiences have taken the form of environmental enrichment and impoverishment (Brown, 1968; Manosevitz, 1970), emotional trauma (Ader \& Schaefer, 1968), undernutrition (Ottinger \& Tanabe, 1968; Slob, Snow, \& Mathot, 1973), drug states (Gauron \& Rowley, 1972), etc. Research has indicated that some of these experiences can adversely affect behavior (e.g., Ottinger \& Tanabe, 1968). In this research, the trend has been to introduce the experience at some early age and then assess its effects on adult behavior. While this approach allows for the determination of adverse effects, it does not permit asking whether or not certain effects are reversible and, if they are, what can be done to enhance recovery. In the adult, behavior or the potential for a behavior is sometimes difficult to alter because of either an organ's loss of plasticity or the incompatibility of a particular behavior with other established behavior patterns. Thus, in adulthood, some apparently irreversible effects may be only indirectly related to the early experience and, further, may have been reversible had therapeutic treatment been introduced at the appropriate developmental stage. Awareness of a learning disability or other behavioral impairment at the earliest postnatal stage could, therefore, offer maximum opportunity for corrective therapy. Such an awareness, however, requires knowledge of tasks appropriate for very young animals. Since the rat has been an animal frequently used in the "early-experience" research, and since relatively little information on the learning capability of neonatal rats is available, this report describes an apparatus and procedures for the effective instrumental training of escape and avoidance behaviors in neonatal and infant rats.

\section{METHOD}

\section{Apparatus}

The apparatus, a shock well, consisted of a 10-cm-sq grid floor surrounded by $2.5-\mathrm{cm}$-high acrylic walls, at the top of which were $6-\mathrm{cm}$-wide felt-covered platforms. The grids that comprised the floor were 1-mm-diam stainless steel rods spaced $4 \mathrm{~mm}$ apart, center to center. The rods were wired to a commercial shock generator and scrambler (Harvard Instruments, Model H.I. 3121). A bottomless $10 \times 10 \times 9 \mathrm{~cm}$ clear acrylic box with a removable top (restraining device) fitted into the well to prevent the rat from climbing the well walls prior to shock onset during escape training.

\section{Procedure}

The response to have been learned in this apparatus was one of climbing the $2.5-\mathrm{cm}$-high wall to avoid or escape shock. A climb was defined operationally as $3 \mathrm{ft}$ on the platform or the animal's entire body off the grids, whichever occurred first. Rats of the ages for which the apparatus was designed (i.e., 5-10 days of age) typically pull themselves onto the platform with their forelegs. Occasionally, however, one hindleg, along with the forelegs, is placed on the platform and used for thrust. In either case, the rat pup can escape shock before it is entirely on the platform.

Escape Training. The following procedure has been used for the effective escape training of 10 5-day-old and 10 7-day-old Wistar albino rats. Fifteen seconds before the start of a trial, the rat was placed in the well with the restraining device in place. A trial began with the removal of the restraining device and the simultaneous application of a .1-mA scrambled $60-\mathrm{Hz}$ ac shock to the grid floor. The trial and shock were terminated when the rat reached the criterion for a response or after $180 \mathrm{sec}$, whichever occurred first. If the rat failed to reach response criterion within $180 \mathrm{sec}$, it was gently forced onto the platform (forced trial). Few, if any, of these forced trials were necessary in the training of animals 5 days of age and older. At shock offset, the rat was immediately removed from the platform and held in E's closed hand for 30 sec. Holding the rat pup in this manner was an attempt to offset the body temperature drop that would normally occur over the training session. At the end of the $30-\mathrm{sec}$ period, the rat was again placed in the escape well with the restraining device in place to await the start of the next trial. This procedure was followed for 25 trials.

Avoidance Training. Thirty avoidance training trials were given to each of five male and five female 10-day-old Wistar albino rats, each rat having been randomly selected from a different litter. A trial began by placing the rat in the center of 
the well on the grid floor. The rat then had $15 \mathrm{sec}$ in which to avoid shock by climbing the $2.5-\mathrm{cm}$ wall onto the platform. If the animal reached the criterion for an avoidance response (AR), it was immediately removed from the platform and held in the E's closed hand. If the rat failed to reach the criterion for an AR within the allotted 15 -sec period, a $.1-\mathrm{mA} 60-\mathrm{Hz}$ ac shock was automatically applied to the grid floor. The shock continued until the animal climbed the wall or for $180 \mathrm{sec}$, whichever occurred first. If the rat did not climb the wall within $180 \mathrm{sec}$ after shock onset, it was prompted as in the escape training procedure. In all cases, the intertrial interval was $45 \mathrm{sec}$.

Ten rats, each of which was a like-sex littermate of one of the trained Ss, served as a control for excitatory effects and possible nonassociative sensitization to environmental stimuli produced by electric shock. These control Ss were also given 30 trials in the apparatus with $45-\mathrm{sec}$ intertrial intervals. Handling during these intervals was the same as that of the trained Ss. For the first 20 trials, however, a modified yoked control procedure was followed. Each control rat was placed on the grids in the center of the well, which was then covered by a clear acrylic lid to prevent the rat from climbing out of the well either prior to or during the application of shock to the grids. On each of these trials, the control rat remained on the grids for the same amount of time and received the same amount of shock as its trained littermate received on its comparable trial. During the last 10 trials, the normal training procedure was followed to determine if the prior shock and handling would enhance the climbing response to the same degree as that observed in the trained Ss during their last 10 trials.

\section{RESULTS}

\section{Escape Training}

The response measure obtained during escape training was the time, to the nearest $.1 \mathrm{sec}$, it took the rat from the start of the trial to reach the criterion for a climb. The reciprocal of each time score (response speed) was computed and averaged for blocks of five trials. Group averages for each trial block were $.20, .29, .32, .33, .27$, and $.34, .38, .44, .41, .47$ for the 5 -day and 7 -day Ss, respectively. A 2 by 2 by 5 factorial analysis of variance was performed on the speed data with age, sex, and trial blocks the factors considered. Only the main effects of age $(\mathrm{F}=8.91, \mathrm{df}=1,16 ; \mathrm{p}<.01)$ and trial block $(\mathrm{F}=$ $9.00, \mathrm{df}=4,64 ; \mathrm{p}<.001)$ were significant. These results indicate that, while the 7-day Ss responded faster than the 5-day Ss, both age groups improved performance over the training session at the same rate.

\section{Avoidance Training}

The response measure of interest for the avoidance training sessions was the number of ARs per five-trial block. The group averages for the trained Ss were for Trial Blocks 1-6, respectively, 0, .6, 1.3, 2.6, 2.9, and 2.5. An analysis of variance performed on these data showed trial block to be the only significant factor $(\mathrm{F}=$ $14.27, \mathrm{df}=5,40 ; \mathrm{p}<.0005)$. The group averages for the yoked controls were for Trial Blocks 5 and 6 , respectively, .4 and .8. An analysis for a partial hierarchal split-plot design (litter nested under sex, all other factors crossed with repeated measures on the trial block factor) was performed on the data from the first two trial blocks of the trained Ss and the training data, i.e., Trial Blocks 5 and 6 , of the yoked control Ss to determine if the 20 previous shock and handling experiences of the controls affected their performance during their 10 training trials. A similar analysis of the data from the last 10 training trials (Blocks 5 and 6) of the trained Ss and the training trials (Blocks 5 and 6 ) of the controls was also performed to determine if training per se exerted an effect in addition to any effect that might obtain from shock and handling alone. These analyses showed that the performance of the yoked controls on Blocks 5 and 6 did not differ significantly ( $F$ $=0.56, \mathrm{df}=1,8 ; \mathrm{p}>.1)$ from that of the trained animals on Blocks 1 and 2, but that the performance of the trained Ss on Blocks 5 and 6 was significantly superior to that of the controls $(F=17.51, \mathrm{df}=1,8 ; \mathrm{p}<.0005)$. These findings suggest that the shock and handling experiences were not sufficient to produce the intrasession increment in avoidance behavior observed in the trained Ss.

\section{DISCUSSION}

The results of this study indicate that the apparatus described herein can be used for the effective escape and avoidance training of neonatal and infant rats. While other apparatuses have been used for the instrumental training of neonatal rats (e.g., Goldman \& Tobach, 1967; Misanin, Nagy, \& Weiss, 1970), the present apparatus is, in several respects, more appropriate for such use. Firstly, the response required in this apparatus, i.e., climbing, is high on the rat's response hierarchy in an aversive situation. This is apparently true of both adult (Bolles, 1973) and neonatal (Misanin, Haig, Hinderliter, \& Nagy, 1973) rats. In this respect, this apparatus, if scaled to the size of the rat, is also appropriate for the instrumental training of rats along the entire age continuum. A similar apparatus has, in fact, been used with adult rats (Maatsch, 1959). Secondly, there is no directional component (Kukleta, 1968) of the escape response in this apparatus as there is in apparatuses such as the straight alley (Misanin, Rose, \& Hinderliter, 1971), shuttlebox (Goldman \& Tobach, 1967), and T-maze (Misanin et al, 1973). Very young animals, therefore, acquire the desired response quite readily. Thirdly, since climbing is high on the rat's response hierarchy and since the response in this apparatus is acquired quite readily, the young rat experiences less aversive stimulation than it would in apparatuses such as the straight alley, shuttlebox, or T-maze. This factor reduces the probability of sensitization to environmental stimuli, habituation to shock, and fatigue. Lastly, with the present apparatus, the measures taken to infer learning are conventional measures unlike those that have been used with the straight alley (e.g., Misanin, Nagy, Keiser, \& Bowen, 1971).

\section{REFERENCES}

Ader, R., \& Schaefer, A. Effects of early experience on one-trail avoidance conditioning. Psychonomic Science, 1968, 10, 235-236.

Bolles, R. C. The comparative psychology of learning: The selective association principle and some problems with "general" laws of learning. In Gordon Bermant (Ed.), Perspectives on animal behavior. Glenview, Ill: Scott, Foresman, 1973. Pp. 280-306.

Brown, R. T. Early experience and problem solving ability. Journal of Comparative \& Physiological Psychology, 1968, 65, 433-440.

Gauron, E. F., \& Rowley, V. N. Critical periods for drug administration in infancy. Psychopharmacologia, 1972, 26, 73-78.

Goldman, P. S., \& Tobach, E. Behaviour modification in infant rats. Animal Behaviour, 1967, 15, 559-562. 
Kukleta, M. Memory components of shock escape reaction in rat. Physiology \& Behavior, 1968, 3, 773-776.

Krech, D., Rosenzweig, M. R., \& Bennett, E. L. Relations between brain chemistry and problem solving among rats raised in enriched and impoverished environments. Journal of Comparative \& Physiological Psychology, 1962, 55, 801-807.

Manosevitz, M. Early environmental enrichment and mouse behavior. Journal of Comparative \& Physiological Psychology, $1970,71,459-466$

Maatsch, J. L. Learning and fixation after a single shock trial. Journal of Comparative \& Physiological Psychology, 1959, 52 , 408-410.

Misanin, J. R., Haigh, J. M., Hinderliter, C. F., \& Nagy, Z. M Analysis of response competition in discriminated and non-discriminated escape training of neonatal rats. Journal of Comparative \& Physiological Psychology, 1973, 85, 570-580.

Misanin, J. R., Nagy, Z. M., Keiser, E. F., \& Bowen, W. Emergence of long-term memory in the neonatal rat. Journal of Comparative \& Physiological Psychology, 1971, 77, 188-199.

Misanin, J. R., Nagy, Z. M., \& Weiss, E. M. Escape behavior in neonatal rats. Psychonomic Science, 1970, 18, 191-192.

Misanin, J. R., Rose, S. J., \& Hinderliter, C. F. Escape behavior in neonatal rats: Methodological and psychometric considerations. Behavior Research Methods \& Instrumentation, 1971, 3, 253-254.

Ottinger, D. R., \& Tanabe, G. Maternal food restriction: Effects on offspring behavior and development. Developmental Psychobiology, 197, 6, 177-186.

Slob, A. K., Snow, C. E., \& Mathot, E. N. Absence of behavioral deficits following neonatal undernutrition in the rat. Developmental Psychobiology, 1973, 6, 177-186.

(R eceived for publication June 6, 1974.)

\title{
Word length and exposure time effects on the recognition of bilaterally presented words*
}

\author{
KATHLEEN M. GILL and WALTER F. McKEEVER \\ Bowling Green State University, Bowling Green, Ohio 43403
}

\begin{abstract}
Word length (two, three, four, and five letters) and exposure time (25, 50, and $100 \mathrm{msec})$ effects on visual half-field recognition performances were studied in a bilateral word presentation paradigm. Significant right-field recognition superiority (RFRS) obtained for all length-exposure time conditions except that for two-letter words exposed for $100 \mathrm{msec}$. RFRS was significantly greater for each of the two longer word lengths than for the two shorter lengths and for the 25-msec exposures than for the 50or 100-msec exposures. The magnitude of RFRS was substantially correlated with a "perceptual difficulty" measure (the ratio of the number of milliseconds available for viewing to the number of letters to be viewed). Results were seen as compatible with a hemispheric asymmetry hypothesis and a differential half-fields masking susceptibility mechanism.
\end{abstract}

Research on lateral visual half-field (VHF) recognition efficiency differences for letter and word stimuli has established that (1) unilateral stimulus presentation yields a right visual half-field (RVF) recognition superiority (Mishkin \& Forgays, 1952; Heron, 1957; Bryden, 1966; McKeever, 1971; and others); (2) bilateral presentation, with fixation controlled, yields a RVF recognition superiority of greater magnitude than obtained in unilateral presentation (McKeever, 1971; Sperry \& Teng, 1973; Olson, 1973); and (3) RVF superiority is not due to order of report bias (McKeever, 1971).

*Supported by Research Grant NS10214-02 from the National Institute of Neurological Diseases and Stroke, National Institutes of Health, to the second author.
Prominent among the factors whose effects might be expected to be well established are word length and exposure durations. Surprisingly, only one experiment has systematically varied word length in lateralized presentation (Bouma, 1973) and no systematic study of the effects of exposure time has been reported for lateralized words. ${ }^{1}$

Within the lateral dominance model of half-field recognition efficiency differences it has been suggested (McKeever \& Huling, 1971; Hines, 1974) that the need to transfer left visual field (LVF) stimulation from the right to the left cerebral hemisphere, in order to allow vocal report of that stimulation, might result in more extensive LVF information loss for longer words and for briefer exposures. Such stimulus trace degradation in 